\title{
The critical role of learning from investigating and debriefing adverse events
}

\author{
Siva Raja ${ }^{1}$, Virginia R. Litle ${ }^{2}$ \\ ${ }^{1}$ Center for Esophageal Diseases, Heart and Vascular Institute, Cleveland Clinic Foundation, Cleveland, OH, USA; ${ }^{2}$ Department of Surgery, Boston \\ Medical Center, Boston University School of Medicine, Boston, MA, USA \\ Contributions: (I) Conception and design: Both authors; (II) Administrative support: Both authors; (III) Provision of study materials or patients: None; \\ (IV) Collection and assembly of data: Both authors; (V) Data analysis and interpretation: Both authors; (VI) Manuscript writing: Both authors; (VII) \\ Final approval of manuscript: Both authors. \\ Correspondence to: Dr. Virginia R. Litle, MD. Division of Thoracic Surgery, Department of Surgery, Boston University, 88 East Newton Street, \\ Collamore Building, Suite 7380, Boston, MA 02118, USA. Email: Virginia.litle@bmc.org.
}

\begin{abstract}
Debriefing after and learning from adverse surgical events is becoming an integral component of our clinical practices and hospital systems. Morbidity and mortality conferences have been the foundation for this process; however, the approach has evolved to be more constructive with root cause analyses and identification of action items to prevent future adverse events. Additional quality improvement resources include the voluntary National Surgical Quality Improvement Program (NSQIP) and the Society of Thoracic Surgeons (STS) databases, which provide seeds for a systematic process of improving patient care. With large databases come not only a route for studying outcome expectedness but also an objective numeric source for development of risk scores to stratify patients and assist with shared decision making. There is also recognition of the collateral damage of adverse events, which, includes the second victims defined as the individuals other than the patient. After an adverse event the second victim can either thrive, just survive or drop-out, and institutional systems should be in place to care for this victim and prevent their travel down the road to burnout. As a contemporaneous topic, burnout impacts not only surgeon wellness but also negatively affects the clinical workforce, which includes nurses in addition to physicians. "To err is human" but to care is ethereal.
\end{abstract}

Keywords: Adverse events; debriefing; thoracic surgery

Submitted Apr 07, 2020. Accepted for publication Jul 10, 2020.

doi: $10.21037 /$ jtd-2020-epts-01

View this article at: http://dx.doi.org/10.21037/jtd-2020-epts-01

\section{Introduction}

"Those who do not remember the past are condemned to repeat it" is a notable quote from the Spanish philosopher George Santayana, which was later modified and made famous by Sir Winston Churchill. Mistakes are part of human history but progress is made from our thoughtful introspection which allow us to learn from our mistakes and forge a better path. This idea of examination of adverse events started over a century ago in medicine and has evolved to a process that has been transformative in improving the delivery of medical care to a point that one would expect it to be almost unrecognizable to its original architects. While other fields like the computer software and the airline industries have adopted this philosophy, their different perspective has facilitated its necessary evolution that could in turn benefit the current processes in medicine.

\section{History}

The roots of the debriefing process for adverse events in medicine can be traced back to the anesthesia records of then medical students Harvey Cushing and Ernest Codman (1). As medical students these two future legends in and out 
of the operating theatre started maintaining meticulous anesthesia records in attempts to improve the care they were delivering to their patients at a time when the delivery of anesthesia was arguably as risky as the surgery it was meant to facilitate. The exact reason for starting this project, while controversial, will likely be lost to medical lore but it ultimately led to Dr. Codman starting the first mortality and morbidity conference $(M \& M)$ at the Massachusetts General Hospital (2). The original ideas behind these conferences were primarily born of the notion that complications may be the result of variable surgeon performance. As such, it may have been the earliest attempts at creating a "standard practice".

\section{Contemporary M\&M}

This idea that much of the complications can be attributable to one person's action or judgment has been the underlying theme of many $M \& M$ for generations and perhaps to some degree even in the current era. A recent publication from 2017, found that even today a significant number of lessons learned from these exercises focus on intraoperative technical performance (3). It is not until the publication of the landmark article from the Institute of Medicine "To Err is Human" in which the authors highlighted the fact that nearly 100,000 deaths a year could be linked to medical errors, that we in medicine started to think beyond the individual (4). From this was born the notion that if perhaps we individually are prone to mistakes, collectively we might do better.

Surgical tradition is to acknowledge and learn from one's role in an adverse outcome with the help of the immediate medical and surgical peer group. The innovative aspect is to create a system that allows everyone to learn from a mistake that may or may not be their own. Tradition and innovation have found a way to coexist in medicine. A significant number of scholarly articles have been published on improving the structure and education value of $M \& M(5-8)$. The unifying themes involve identifying the preventable adverse outcome, highlighting the gaps in the current process that facilitated the outcome and offering quality improvement metrics to provide benchmarks for improvement.

\section{Identifying preventable adverse outcomes}

The effectiveness of the $M \& M$ conference as a tool for examining adverse events is based on cases chosen for discussion as much as the ability of the professional staff to have an open dialogue. Currently, cases are chosen for discussion by trainees in many academic institutions while others choose from a standard list of mortality and "never events" like line infections, leak, pressure ulcers and venous thromboembolisms (5). To maximize the learning opportunity, a review by a senior member of the medical or surgical staff can help triage cases based on their educational potential in terms of a "teaching moment" outside of mortalities which usually cannot be skipped. A structured analysis and presentation are also vital (6). Additionally, in order to understand a complication we need to first agree on common nomenclature and grading of severity. A recent systematic review on neurosurgery $M \& M$ found that no standardization was found among studies in terms of grading or inclusion of comorbidities to a point where comparisons were not possible (9).

\section{Investigating process measures}

Sustainability of lessons learned from M\&M is only possible if it extends beyond the level of the individual to the level of the system. These are the measures that allow one to create both institutional memory than can transcend an individual as well as create process measures that help prevent this independent of the individual. Many would argue that once that preventable adverse event has been identified, a root cause analysis (RCA) should be conducted (10). The major benefit of this intervention is that it often eliminates "shame and blame" element that can be a part of M\&M. By de-emphasizing the personal responsibility, it allows the entire group to come together to identify the system failure that can hopefully be remedied. As an example, when a retained sponge is identified post-operatively on the last case of the night, one can envision a scenario in which the surgeon blames the scrub technician for the miscount and the circulating nurse blames the surgeon for rushing their count. This almost never results in an outcome where this can prevent the next retained sponge with this team or any other. Instead, had the focus been on the preventing the next retained sponge rather than just this event, perhaps the team could have found a collaborative solution.

The RCA should have several key components within it to be effective. It must have (I) a clear description of the failure, (II) understanding the contributory factors, (III) a list of all accountable parties, (IV) a corrective action 
plan, (V) implementation plan and lastly (VI) a review mechanism to evaluate the compliance/success of the implementation plan.

Using this plan with regards to the above scenario, an RCA should (I) Identify the retrained sponge as the sentinel preventable event, (II) identify multiple hand offs, late time of night, desire for the team to go home and perceived pressure by the staff surgeons as contributory factors, (III) assign the surgeon, surgical resident, surgical scrub technician and the circulating nurse as equal and accountable parties, (IV) create a surgical pause prior to closure where there is a hard stop to the case till the counts have been verified, (V) implement this pause in all cases in the enterprise and (VI) make the failure to have a pause as reportable and hence measurable metric to be evaluated every six months for effectiveness in preventing retained foreign bodies as well as for rates of compliance. Creating a process or a check list is a system level change that helps prevent this adverse event for all the surgical teams in the enterprise.

If we want this type of analytical approach to become incorporated into the genetics of the surgical culture just as the surgical M\&M has become, we need to educate our trainees at an early stage in both its use and its value. Many structured exercises such as the Ishikawa fishbone diagram for cause effect analysis exist to facilitate this process (11). Feedback from case simulation-based education for residents on the use of RCA clearly demonstrates their appreciation for the value of the process in reducing medical errors and as a constructive way to analyze medical errors (12). More interestingly, the residents also identified an issue with "buy in" at all levels as a barrier to implementation. As such, routine use of the approach to analysis of adverse events can only happen if it can become core component of the "surgical culture".

\section{Quality improvement Databases}

From the concept of progress through systematic improvement were born quality improvement databases such as the National Surgical Quality Improvement Program (NSQIP) and the Society of Thoracic Surgeons (STS) database. These are voluntary databases that are risk adjusted and validated to provide expected outcomes for commonly performed general surgery and thoracic surgery procedures. This allows for continuous feedback that can allow problem areas to be identified and start the process towards improvement.

\section{Legal landscape}

The need to discuss and learn from adverse events has been a part of modern medicine for the better part of the last century as noted above. The barriers to open discourse have always been from a punitive stand point, both professionally and legally. The change in focus towards process improvements help alleviate concerns for professional blame. However, legal concerns have required states to enact their own measures for protecting the peer review privilege and confidentiality [Virmani v. Novant Health, Inc., 259 F3d 284, 290 (4th Cir 2001)]. Unless needed for matters relating to discrimination, the comments made during the peer review process concerning an adverse medical outcome cannot be used for purposes of medical malpractice litigation.

\section{Building a better mouse trap}

"Without continual growth and progress, such words as improvement, achievement, and success have no meaning" penned Ben Franklin. Our processes for the critical evaluation of adverse events has progressed far since its inception. We have elevated the investigation of adverse events from assigning individual blame to identifying system level flaws that need to be remedied while also using "Big data" in the form of quality improvement databases. As noted by Ben Franklin, this is not the end of what we seek. In fact, it is merely a way point in our perpetual quest for betterment. This is where, we contend that it is no longer enough to learn from adverse events but also learn from near misses and unexpected success. The idea of "outcome expectedness" was introduced by Bohnen and colleagues (13). They describe scenarios which allows us to both learn for "unexpected successes and failure" which are arguably the richest source of learning. While learning can be found everywhere, the scenario involving the death of a patient after a devastating motor vehicle accident may be less enlightening than the case of a patient undergoing an elective hiatal hernia operation presenting with a delayed esophageal leak after a normal post-operative swallow. Additionally, our ability to use databases such NSQIP and STS allow us to assign risk score to prioritize valuable 
opportunities for quality improvement.

\section{The buman cost and the second victim}

When adverse events occur and especially when harm has been done to the patient, the focus has rightfully been on the patient and their family. However, hidden in that picture is the often unrecognized second victim, the involved caregiver(s) who suffers psychological harm from having participated in that event (14). In a survey-based study, the authors identified six stages of recovery from adverse events (15). These are (I) chaos and accident response, (II) intrusive reflections, (III) restoring personal integrity, (IV) enduring the inquisition, (V) obtaining emotional first aid and (VI) moving on. The outcome for the last stage of "moving on", which is entirely dependent on how the steps above are managed, can consist of thriving, surviving or dropping out. Obviously, the desired outcome is one where the healthcare professional continues to thrive in their chosen profession. Acknowledging the presence of the "second victim" allows organizations to put in place support mechanisms including professional coaching and mental health access to aid in their recovery. The most undesirable option is the "dropping out" due to burnout from this event which includes moving to a different practice/location up to leaving the profession entirely. The financial cost to the health care system to replace that caregiver is enormous (16). However, the personal cost to the individual incalculable.

\section{Future directions}

Thus far, all of our analyses of critical failures remain retrospective. It is in this arena, that other professions have shown the value analyzing both the successes and failure with an eye for improvement. Pilots (military and civilian) always debrief after every mission or flight. They talk about what went wrong, what went right and if anything could have been done better! In the surgical world we almost never take the time to debrief at the end of every surgery other than to agree on details such as estimated blood loss, possible specimens and perhaps the patient's destination upon leaving the operating room (OR). This brief exercise that is so valuable to so many other fields, may allow us to prevent problems in the surgical world that have yet to occur. As more technology enters the OR, access to video of the procedure can also help this debriefing process become more objective and less subjective.

The logical extension of preventing failure is to predict future failures and solve them before they have had a chance to occur and cause harm. This is a strategy known as "penetration testing" in the cyber world where cyber-attacks by ethical hackers are simulated to allow one to look for weaknesses in the existing or new networks. In surgery, we have yet to be this proactive. Perhaps it is because we do not have the time in our busy schedules, we may be approaching burn out or because there are too many handoffs for this to be meaningful. As such, the last adverse event we should seek to prevent with critical thinking is the loss of wellness due to the imbalance in our work life balance. As a specialty filled with intelligent individuals, we have to try so that we may succeed.

\section{Acknowledgments}

Funding: None.

\section{Footnote}

Provenance and Peer Review: This article was commissioned by the Guest Editor (Alessandro Brunelli and Enrico Ruffini) for the series "European Perspectives in Thoracic Surgery (2020) - the Seven Edition" published in fournal of Thoracic Disease. The article has undergone external peer review.

Conflicts of Interest: Both authors have completed the ICMJE uniform disclosure form (available at http://dx.doi. org/10.21037/jtd-2020-epts-01). The series "European Perspectives in Thoracic Surgery (2020) - the Seven Edition" was commissioned by the editorial office without any funding or sponsorship. Dr. SR reports personal fees from Smiths Medical, outside the submitted work. Dr. VRL has no other conflicts of interest to declare.

Ethical Statement: The authors are accountable for all aspects of the work in ensuring that questions related to the accuracy or integrity of any part of the work are appropriately investigated and resolved.

Open Access Statement: This is an Open Access article distributed in accordance with the Creative Commons Attribution-NonCommercial-NoDerivs 4.0 International License (CC BY-NC-ND 4.0), which permits the noncommercial replication and distribution of the article with the strict proviso that no changes or edits are made and the original work is properly cited (including links to both the 
formal publication through the relevant DOI and the license). See: https://creativecommons.org/licenses/by-nc-nd/4.0/.

\section{References}

1. Sundararaman LV, Desai SP. The Anesthesia Records of Harvey Cushing and Ernest Codman. Anesth Analg 2018;126:322-9.

2. Orlander JD, Barber TW, Fincke BG. The morbidity and mortality conference: the delicate nature of learning from error. Acad Med 2002;77:1001-6.

3. de Vos MS, Hamming JF, Marang-van de Mheen PJ. Learning From Morbidity and Mortality Conferences: Focus and Sustainability of Lessons for Patient Care. J Patient Saf 2021;17:231-8.

4. Kohn LT, Corrigan JM, Donaldson MS. editors. To Err is Human: Building a Safer Health System. 2014/08/01 edition. Washington D.C.: National Academy Press (US), 2000.

5. Sacks GD, Lawson EH, Tillou A, et al. Morbidity and Mortality Conference 2.0. Ann Surg 2015;262:228-9.

6. Mitchell EL, Lee DY, Arora S, et al. Improving the quality of the surgical morbidity and mortality conference: a prospective intervention study. Acad Med 2013;88:824-30.

7. Abdelsattar JM, Mourany J, Afridi FG, et al. Enhancing the Educational Value and Faculty Attendance of a Morbidity and Mortality Conference. J Surg Educ 2020;77:905-10.

8. Nussenbaum B, Chole RA. Rethinking Morbidity and Mortality Conference. Otolaryngol Clin North Am

Cite this article as: Raja S, Litle VR. The critical role of learning from investigating and debriefing adverse events. J Thorac Dis 2021;13(Suppl 1):S3-S7. doi: 10.21037/jtd-2020epts-01
2019;52:47-53.

9. Rybkin I, Azizkhanian I, Gary J, et al. Unique Neurosurgical Morbidity and Mortality Conference Characteristics: A Comprehensive Literature Review of Neurosurgical Morbidity and Mortality Conference Practices with Proposed Recommendations. World Neurosurg 2020;135:48-57.

10. Johna S, Tang T, Saidy M. Patient safety in surgical residency: root cause analysis and the surgical morbidity and mortality conference--case series from clinical practice. Perm J 2012;16:67-9.

11. Ishikawa K, Lotfus JH. Introduction to quality control. 3rd edition. Tokyo, Japan: 3A Corporation, 1990.

12. Ramanathan R, Duane TM, Kaplan BJ, et al. Using a Root Cause Analysis Curriculum for Practice-Based Learning and Improvement in General Surgery Residency. J Surg Educ 2015;72:e286-93.

13. Bohnen JD, Chang DC, Lillemoe KD. Reconceiving the Morbidity and Mortality Conference in an Era of Big Data: An "Unexpected" Outcomes Approach. Ann Surg 2016;263:857-9.

14. Denham CR. TRUST: The 5 Rights of the Second Victim. J Patient Saf 2007;3:107-19.

15. Scott SD, Hirschinger LE, Cox KR, et al. The natural history of recovery for the healthcare provider "second victim" after adverse patient events. Qual Saf Health Care 2009; 18:325-30.

16. Raja S, Stein SL. Work-life balance: history, costs, and budgeting for balance. Clin Colon Rectal Surg 2014;27:71-4. 